\title{
Influence of Dissolved Organic Matter and Invertebrates on the Function of Microbial Films in Groundwater
}

\author{
Timothy J. Cooney $\cdot$ Kevin S. Simon
}

Published online: 16 September 2009

(C) Springer Science + Business Media, LLC 2009

Erratum to: Microb Ecol

DOI 10.1007/s00248-009-9523-y

In the original version of this article, the labels ('present' and 'absent') on the $\mathrm{x}$ axes of the plots in Fig. 3 were inadvertently reversed. The correct version Fig. 3 should appear as:

The online version of the original article can be found at http://dx.doi. org/10.1007/s00248-009-9523-y

T. J. Cooney

Department of Biology, James Madison University,

Harrisonburg, VA 22807, USA

K. S. Simon $(\bowtie)$

School of Biology and Ecology, University of Maine,

Orono, ME 04469-5722, USA

e-mail: ksimon@maine.edu 
Fig. 3 Rates of bacterial production on rocks $(\mathbf{a}, \mathbf{b})$ and fine sediments $(\mathbf{c}, \mathbf{d})$ in the presence and absence of G. minus and either glucose or tannic acid in experiment 2 . Values are means $(n=4)$ with \pm one standard deviation. Pairwise comparisons among means were not conducted, see text for statistical treatment of main effects

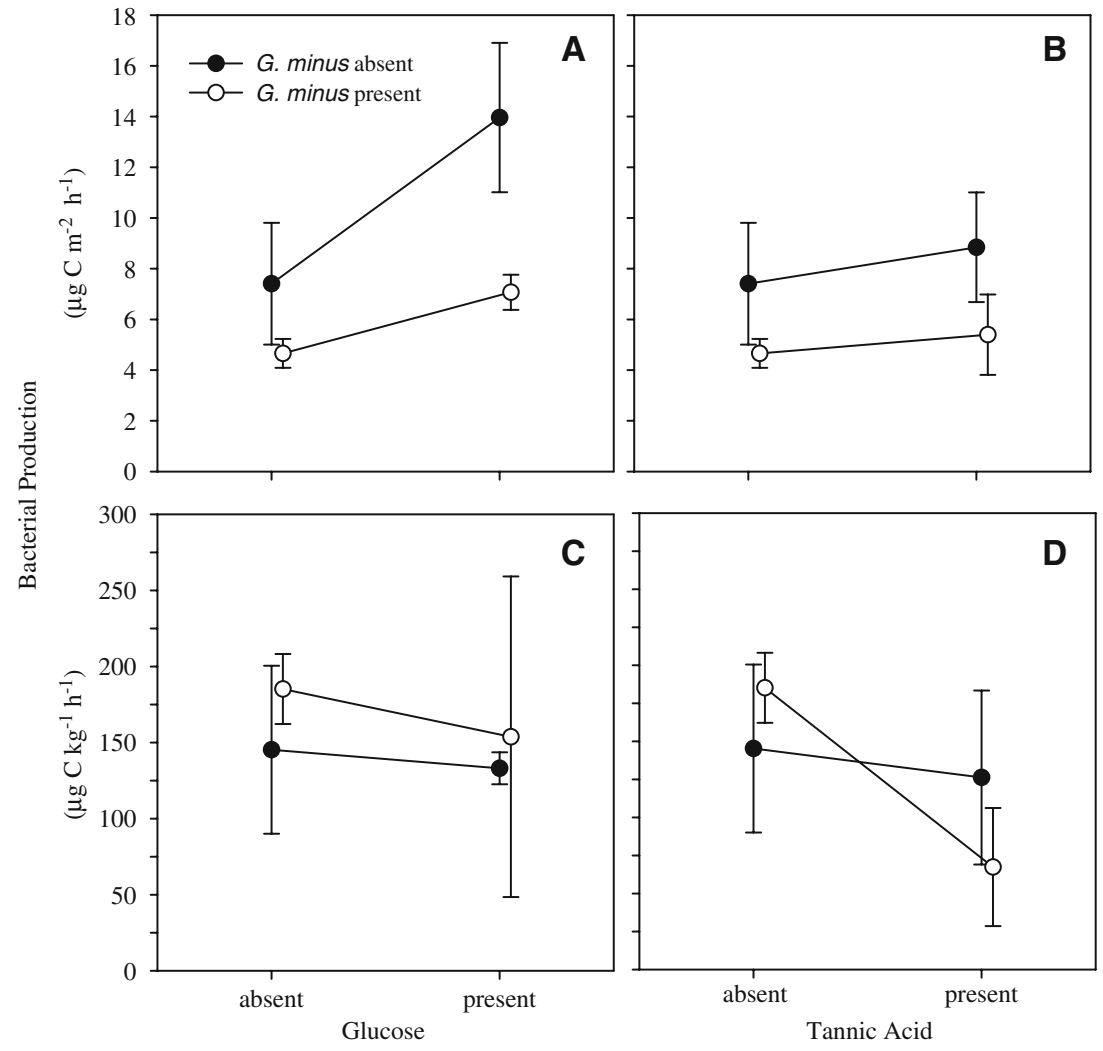

